\title{
Apoptosis induced by methanol extract of Potentilla discolor in human mucoepidermoid carcinoma cells through STAT3/PUMA signaling axis
}

\author{
HYUN-JU YU ${ }^{1 *}$, CHI-HYUN AHN ${ }^{2 *}$, IN-HYOUNG YANG ${ }^{1}$, DONG-HOON WON ${ }^{2}$, BOHWAN JIN $^{3}$, \\ NAM-PYO CHO ${ }^{1}$, SEONG DOO HONG $^{2}, \mathrm{JI}-\mathrm{AE} \mathrm{SHIN}^{2}$ and SUNG-DAE $\mathrm{CHO}^{2}$ \\ ${ }^{1}$ Department of Oral Pathology, School of Dentistry, Institute of Biodegradable Material, Institute of Oral Bioscience, \\ Chonbuk National University, Jeonju, Jeollabuk-do 54896; ${ }^{2}$ Department of Oral Pathology, \\ School of Dentistry and Dental Research Institute, Seoul National University, Seoul 03080; \\ ${ }^{3}$ Laboratory Animal Center, CHA University, CHA Biocomplex, Sampyeong-Dong, \\ Seongnam, Gyeonggi 13488, Republic of Korea
}

Received July 5, 2017; Accepted January 16, 2018

DOI: $10.3892 / \mathrm{mmr} .2018 .8468$

\begin{abstract}
Potentilla discolor has been used in traditional Chinese medicine for the treatment of hyperglycemia. However, the potential role of Potentilla discolor against cancer and its mode of action remain to be fully elucidated. The present study explored the apoptotic effect of methanol extract of Potentilla discolor (MEPD) in human mucoepidermoid carcinoma (MEC) cell lines of salivary glands. MEPD markedly suppressed the growth and induced apoptotic cell death in MC3 and YD15 cells. MEPD treatment significantly upregulated the expression of PUMA and reduced STAT3 phosphorylation. Overexpression of STAT3 partially recovered the growth of MEC cells inhibited by MEPD. In addition, dephosphorylation of STAT3 by cryptotanshinone (a potent STAT3 inhibitor) was sufficient to inhibit the growth of MEC cells and induce apoptosis via affecting PUMA protein. These results suggest that MEPD has a potential anticancer property via the STAT3/PUMA signaling axis in human MEC cells of salivary gland.
\end{abstract}

Correspondence to: Dr Ji-Ae Shin or Dr Sung-Dae Cho, Department of Oral Pathology, School of Dentistry and Dental Research Institute, Seoul National University, Seoul 03080, Republic of Korea

E-mail: sky21sm@snu.ac.kr

E-mail: efiwdsc@snu.ac.kr

*Contributed equally

Key words: Potentilla discolor, mucoepidermoid carcinoma cell line, apoptosis, PUMA, STAT3

\section{Introduction}

Salivary gland tumors are a rare group of tumors that comprise almost $5 \%$ of head and neck cancers and $\sim 0.5 \%$ of all malignancies (1) and they differ in their responsiveness to anticancer therapies because of their heterogeneities in their phenotypic, biological and clinical behavior (2). Mucoepidermoid carcinoma (MEC) is the most common malignant salivary gland tumor in adults and children and usually affects the parotid and minor salivary glands. Surgery is the most common treatment for MEC, but often results in diminishing the quality of life by devastating functional and cosmetic consequences (3). Thus, it is necessary to develop promising chemotherapeutic agents to kill residual tumor cells and prevent the recurrence of MEC.

For centuries, medicinal natural products have been regarded as precious sources of chemotherapeutic agents, and still lots of medicines are originated from plant-derived natural products $(4,5)$. Over the past, plant-derived natural products or their single components have been currently employed for the treatments of various diseases $(6,7)$. They have anti-neoplastic potentials as suitable candidates for extending the range of therapeutic options for several types of cancers (8). Recently, our research demonstrated that natural products induce apoptotic cell death in human oral cancer cell lines. For examples, methanol extracts of Dianthus chinensis and Acalypha australis L. target specificity protein 1 (Sp1) to induce apoptosis (9) and Impatiens balsamina L. promotes apoptosis by downregulation of Akt pathway in human oral cancer cells (10). Several papers also reviewed the beneficial of natural products for the treatment of oral cancer, for which current treatment approaches have not succeeded in improving long-term clinical outcome $(11,12)$. These suggest that natural products may be promising chemotherapeutic drug candidates for treatment of oral cancer. Potentilla discolor of the rosaceae commonly founded in the north temperate, is a noticed traditional Chinese medicine $(13,14)$. It has been also reported to improve the complications of diabetes mellitus in 
both experimental animals and clinical trials (15). However, the anticancer role of Potentilla discolor in human mucoepidermoid carcinoma (MEC) cell lines still remains to be determined. Our main objectives were to assess antitumor effects of methanol extract of Potentilla discolor (MEPD) and decipher the molecular mechanism involved in its antitumor activity in human MEC cells.

\section{Materials and methods}

Cell culture and chemical treatment. Salivary gland mucoepidermoid carcinoma MC3 cells which were kindly provided by Professor Wu Junzheng in the Forth Military Medical University (Xi'an, China), were isolated by repeated in situtransplants of MEC-1 human mucoepidermoid carcinoma cell line derived from palatal salivary gland as described in the study by Wen et al (16). YD15 cells were obtained from Professor Jin Kim in Yonsei University (Seoul, Korea), which was derived from salivary gland mucoepidermoid carcinoma of tongue origin (17). MC3 cells were grown in DMEM and YD15 cells were grown in RPMI-1640; both types of media were supplemented with $10 \%$ fetal bovine serum (FBS) and $100 \mathrm{U} / \mathrm{ml}$ each of penicillin and streptomycin in a humidified atmosphere containing $5 \% \mathrm{CO}_{2}$ at $37^{\circ} \mathrm{C}$. An equal number of cells were seeded and allowed to attach. All experiments were performed in cells cultured at 50-60\% confluence. Methanol extract of Potentilla discolor (MEPD) was supplied from Korea Plant Extract Bank at the Korea Research Institute of Bioscience and Biotechnology (Cheongju, Korea), and cryptotanshinone was purchased from Sigma-Aldrich (St. Louis, MO, USA). Each chemical was dissolved in dimethyl sulfoxide (DMSO), aliquoted, and stored at $-20^{\circ} \mathrm{C}$.

Trypan blue exclusion assay. The cytotoxicity of MEPD or cryptotanshinone was determined with trypan blue solution (Gibco, Paisley, UK). Harvested cells were stained with trypan blue $(0.4 \%)$ and then viable cells were counted using a hemocytometer.

Western blot analysis. Whole-cell lysates were prepared with lysis buffer and protein concentration in each sample was measured using a DC Protein Assay Kit (Bio-Rad Laboratories, Madison, WI, USA). After normalization, equal amounts of protein were separated by SDS-PAGE and then transferred to Immuno-Blot PVDF membranes. The membranes were blocked with $5 \%$ skim milk in TBST at room temperature (RT) for $2 \mathrm{~h}$, and incubated with primary antibodies and corresponding HRP-conjugated secondary antibodies (1:5,000; catalog no. SC-2004 for anti-rabbit and SC-2020 for anti-goat). Rabbit anti-human polyclonal antibodies against cleaved PARP (1:3,000; catalog no. 9541), p-STAT3 (1:1,000; catalog no. 9145), total STAT3 (1:3,000; catalog no. 4904) and PUMA (1:1,000; catalog no. 4976) were purchased from Cell Signaling Technology, Inc. (Charlottesville, VA, USA). p53 antibody (1:2,000; catalog no. OP43) was obtained by Calbiochem (San Diego, CA, USA). Goat anti-human actin polyclonal antibody (1:5,000; catalog no. SC-1615) was obtained from Santa Cruz Biotechnology, Inc., (Santa Cruz, CA, USA). The immunoreactive bands were visualized by ImageQuant LAS 500 (GE Healthcare Life Sciences, Piscataway, NJ, USA).
4'-6-Diamidino-2-phenylindole (DAPI) staining. To detect nuclear morphological changes of apoptotic cells, cells were stained with DAPI solution (Sigma-Aldrich). Briefly, cells were fixed in $100 \%$ methanol at RT for $10 \mathrm{~min}$, deposited on slides, and stained with DAPI solution $(2 \mu \mathrm{g} / \mathrm{ml})$. The morphological changes of apoptotic cells were observed under a fluorescence microscopy.

Liveldead assay. The cytotoxicity of MEPD or cryptotanshinone were determined using Live/Dead Viability/Cytotoxicity assay (Life Technologies, Grand Island, NY, USA). The polyanionic dye calcein-AM is retained within live cells, producing an intense green fluorescence through intracellular esterase activity. Ethidium homodimer-1 enters cells with damaged membranes and binds to nucleic acids, producing a bright red fluorescence in dead cells. Briefly, cells were stained with $2 \mu \mathrm{M}$ calcein-AM and $4 \mu \mathrm{M}$ ethidium homodimer-1, and then incubated for $30 \mathrm{~min}$ at RT. Cells were analyzed under a fluorescence microscopy.

Immunofluorescence staining. MC3 and YD15 cells were seeded on 4-well culture plate and treated with DMSO or MEPD. After $24 \mathrm{~h}$, cells were fixed and permeabilized using the cytofix/cytoperm solution for $1 \mathrm{~h}$ at $4^{\circ} \mathrm{C}$. Cells were then blocked with $1 \%$ bovine serum albumin (BSA) in PBS for $1 \mathrm{~h}$ at RT and incubated overnight at $4^{\circ} \mathrm{C}$ with antibodies against p-STAT3 or PUMA. Subsequently, the cells were exposed to the FITC-conjugated secondary antibody for $1 \mathrm{~h}$ at RT and were visualized using a fluorescence microscope equipped with the appropriate filters for DAPI and FITC dyes.

Construction of STAT3 overexpression vector and transient transfection. The open reading frame of human STAT3 (NM_139276) was amplified from cDNA that was synthesized in HSC3 cells using the specific primers of the gene (primer sequence; STAT3 sense, 5'-GATATCATGGCC CAATGGAATCAG-3', with an included EcoRV site, STAT3 antisense, 5'-GATATCTCACATGGGGGAGGTAGC-3', with an included EcoRV site), and then cloned into pGEM $^{\circledR}$ T-easy vector (Promega, Madison, WI, USA). The STAT3 was confirmed by sequence analysis. Finally, the gene was cloned into the multi cloning site of pcDNA3.1 (+) vector (Invitrogen, San Diego, CA, USA). MC3 and YD15 cells were transfected by two kinds of vector constructs (pcDNA3.1; pcDNA3.1-STAT3) by Lipofectamine 3000 transfection reagent (Life Technologies, Carlsbad, CA, USA) according to the manufacturer's instructions, respectively.

Statistical analysis. Student's t-test or one-way ANOVA followed by Tukey's post hoc test were used to determine the significance of differences between the control and treatment groups; P-values of $<0.05,0.01$ or 0.001 are considered significant.

\section{Results}

MEPD suppresses the growth of human mucoepidermoid carcinoma cells of salivary gland by inducing apoptotic cell death. To explore the potential antitumor activities of MEPD in MC3 and YD15 human mucoepidermoid carcinoma (MEC) 

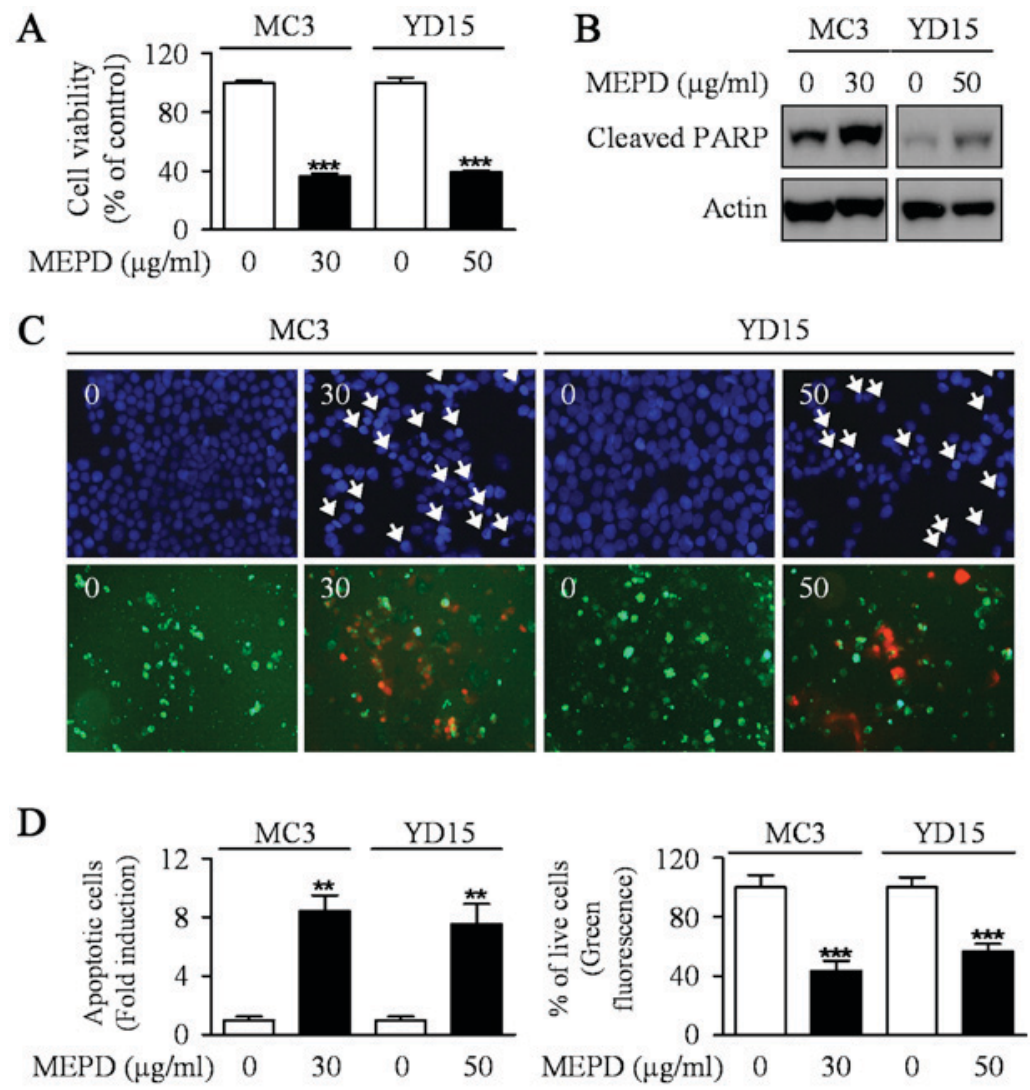

Figure 1. The effects of MEPD on cell viability and apoptosis in human mucoepidermoid carcinoma cells of salivary gland. MC3 and YD15 cells were treated with DMSO or certain dose of MEPD (30 $\mu \mathrm{g} / \mathrm{ml}$ for MC3 cells, $50 \mu \mathrm{g} / \mathrm{ml}$ for YD15 cells) for $48 \mathrm{~h}$. (A) The effects of MEPD on cell viability were analyzed by trypan blue exclusion assay. The graph represents the mean \pm SD of triplicate experiments. (B) Western blot analysis was performed to detect cleaved PARP. Actin was used to normalize the protein loading of each treatment group. (C) Both cells were stained with DAPI solution as mentioned in Materials and methods (magnification, $\mathrm{x} 400$, upper panel). Live (green) and dead (red) cells were determined by Live/Dead assay kit as mentioned in Materials and methods (magnification, x200, lower panel). (D) Nuclei of apoptotic cells (left panel) or Calcein-AM-stained cells (right panel) were counted and the graphs represent the means \pm SD of triplicate experiments. ${ }^{* *} \mathrm{P}<0.05 ;{ }^{* * *} \mathrm{P}<0.01$ compared with DMSO treatment group.

cell lines, we evaluated the growth-inhibitory effects of MEPD using trypan blue exclusion assay after treatment of MEPD ( $30 \mu \mathrm{g} / \mathrm{ml}$ for MC3 cells and $50 \mu \mathrm{g} / \mathrm{ml}$ for YD15 cells) for $48 \mathrm{~h}$. MEPD treatment significantly reduced cell viability in both cells relative to the controls (Fig. 1A). In order to demonstrate the effect of MEPD on apoptosis of MEC cells, we performed western to detect the protein expression level of PARP in both MC3 and YD15 cells. As presented in Fig. 1B, PARP cleaved in both cell lines treated with MEPD. Moreover, qualitative evaluation of apoptotic cell death in MEPD-treated cells was made by DAPI staining (Fig. 1C, upper; Fig. 1D, left) and Live/dead assay (Fig. 1C, down; Fig. 1D, right). The results showed that DNA-fragmented or EthD-1-stained (red fluorescence) cells were observed in MEPD-treated group indicating that apoptosis may be involved in MEPD-mediated growth suppression in MEC cells of salivary gland.

MEPD induces PUMA, but inactivates STAT3. PUMA induced by natural compound is known as one of the main mediators for apoptosis of cancer cells (18). A previous study also reported that exogenous expression of PUMA resulted in suppression of tumor growth by inducing apoptosis in an orthotopic mouse model of oral cancer (19). To investigate whether PUMA is related to MEPD-induced apoptosis, we detected expression level of PUMA protein in MEPD-treated both MEC cell lines. As shown in Fig. 2A, MEPD markedly induced PUMA protein expression. We also visually observed the increase in PUMA expression in MEPD-treated cells using immunofluorescence staining compared to the controls (Fig. 2B). Several recent reports demonstrated that STAT3 represents a target for therapeutic intervention in oral cancer (20-22). Thus, STAT3 signaling was examined after the treatment of MEPD in MEC cell lines. The results demonstrated that MEPD significantly inhibited the expression of phospho-STAT3 evidenced by western blotting and immunofluorescence analysis (Fig. 3A and B). To further clarify the functional role of STAT3 on cell viability in MEC cell lines, we transfected STAT3 overexpression vector into both MEC cell lines. The results showed that STAT3 overexpression slightly brought back MEPD-mediated growth inhibition of MC3 and YD15 cells, but it was statistically significant (Fig. 3C). These results suggest that MEPD-caused growth inhibition may be due to both PUMA and STAT3 signaling in MEC cell lines.

Inactivating STAT3 by cryptotanshinone leads to apoptotic cell death by inducing PUMA expression. Previously, the abrogation of STAT3 was sufficient to induce p53-mediated apoptosis and PUMA is a key mediator in p53-mediated apoptosis $(23,24)$. Hence, we hypothesized that STAT3 may be involved in the induction of PUMA protein during 

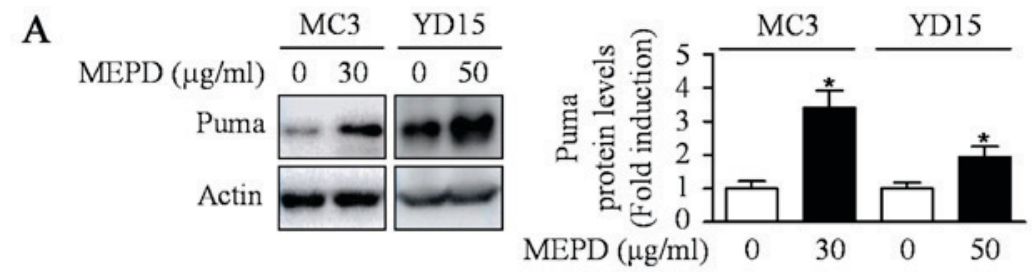

B

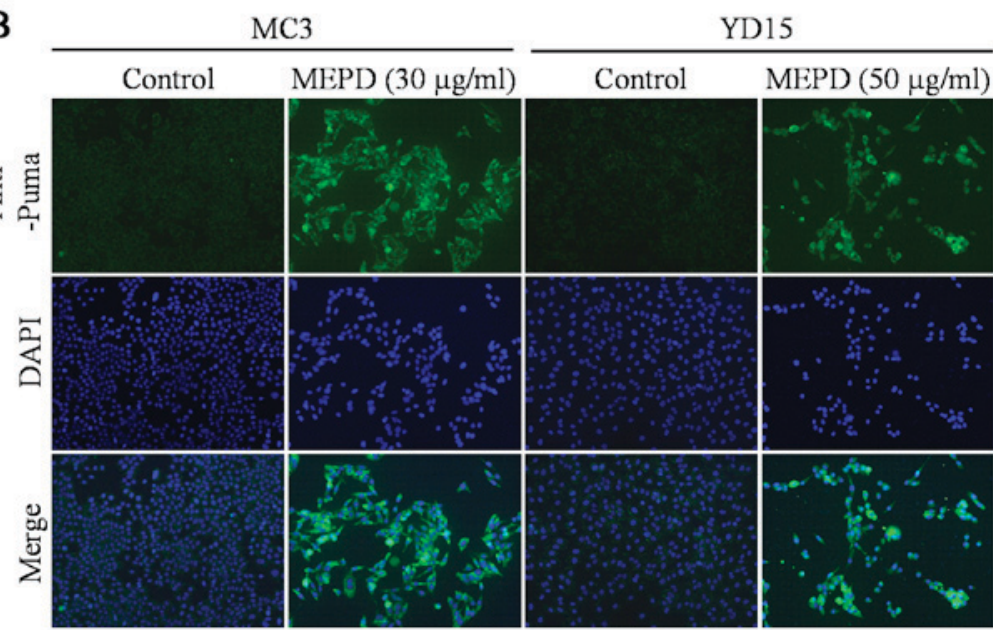

Figure 2. The effects of MEPD on PUMA expression in MC3 and YD15 cells. MC3 and YD15 cells were treated with DMSO or certain dose of MEPD for $48 \mathrm{~h}$. (A) The cell lysates were analyzed by western blotting using PUMA antibody. The graph represents the mean \pm SD of three independent experiments and significance compared with the control group was indicated (" $\mathrm{P}<0.05$ vs. control group). (B) Immunofluorescence was performed using PUMA antibody (magnification, $\mathrm{x} 400$ ).

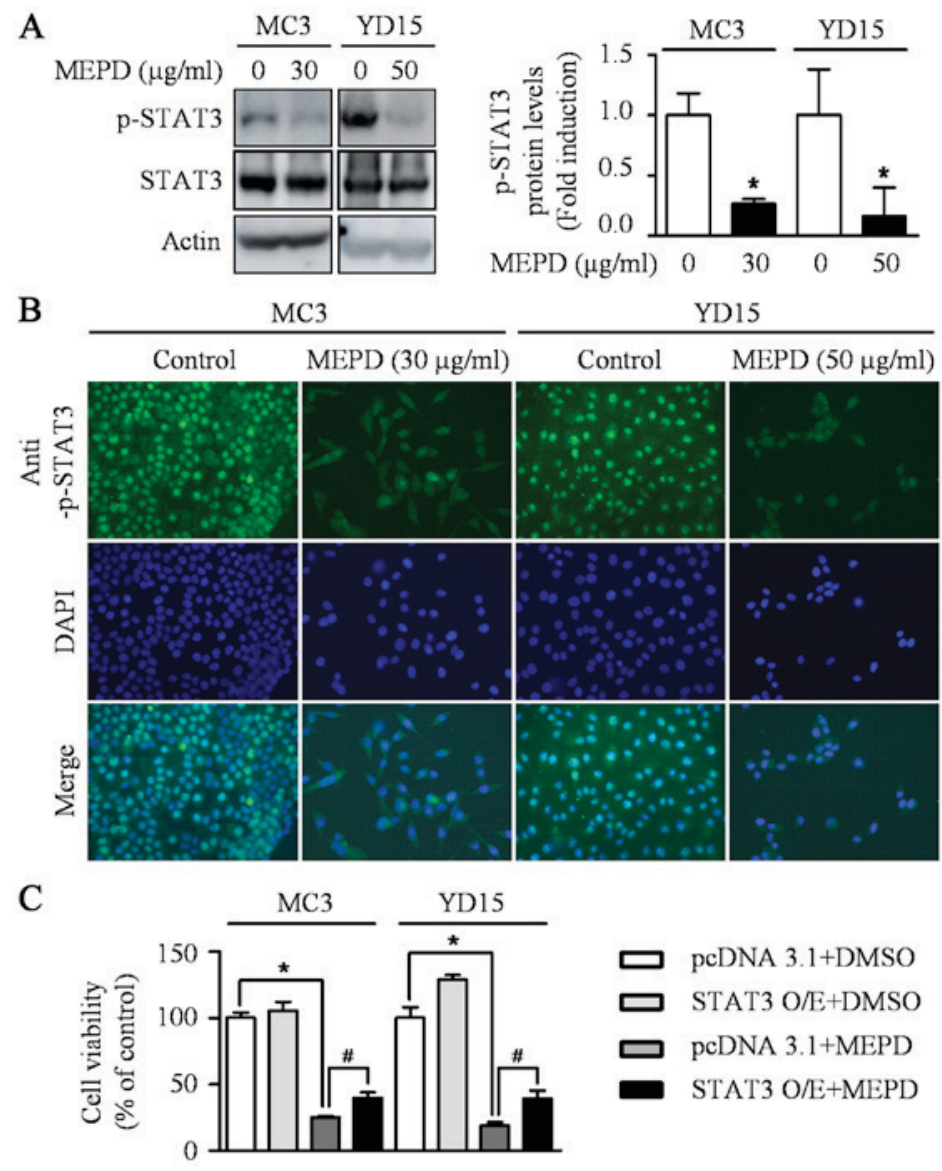

Figure 3. The effects of MEPD on STAT3 phosphorylation in MC3 and YD15 cells. (A) The cell lysates were analyzed by western blot analysis using antibodies against p-STAT3 and total STAT3. The graph represents the mean \pm SD of three independent experiments and significance compared with the control group was indicated ("P<0.05). (B) Immunofluorescence was performed using with p-STAT3 antibody (magnification, $\mathrm{x} 400$ ). (C) Cells were transiently transfected with $500 \mathrm{ng}$ pcDNA3.1 or pcDNA3.1-STAT3 for $24 \mathrm{~h}$ and treated with certain dose of MEPD for $48 \mathrm{~h}$. The cell viability was performed by trypan blue exclusion assay. ${ }^{*} \mathrm{P}<0.05$ compared with DMSO treatment group; ${ }^{*} \mathrm{P}<0.05$ compared with pcDNA3.1 control group. 
A
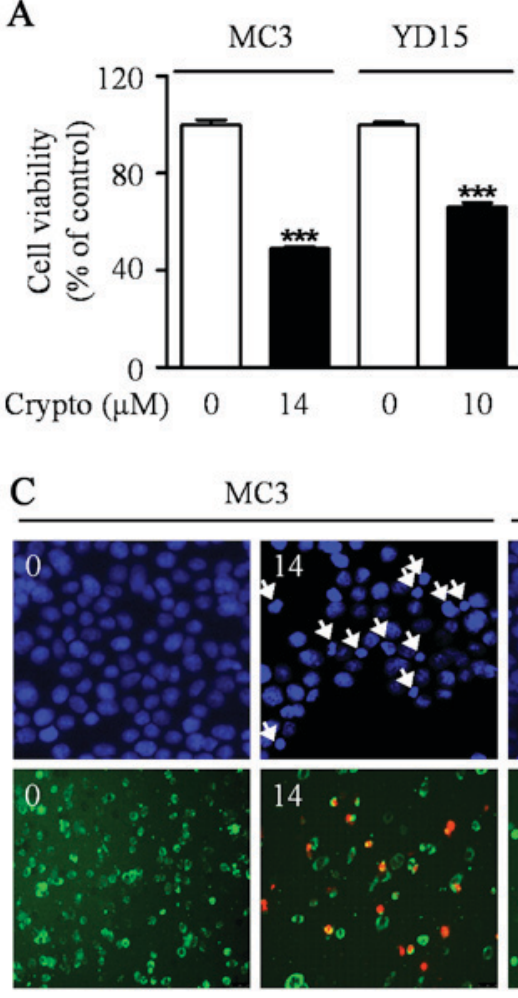

C3
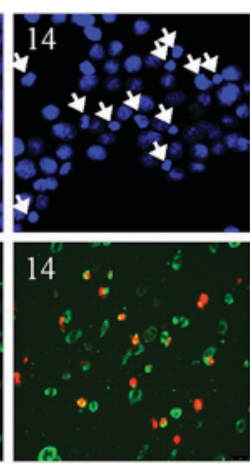

D

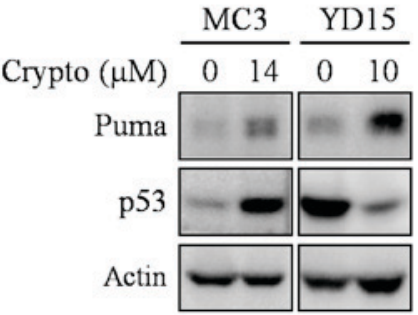

B

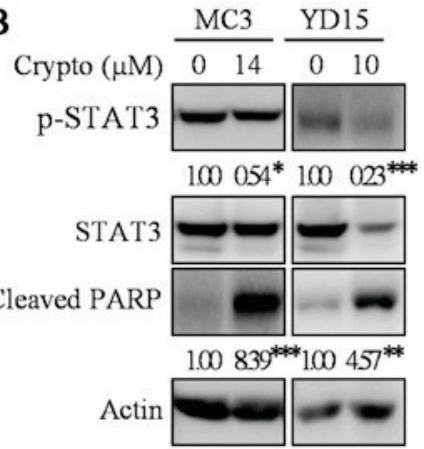

YD15
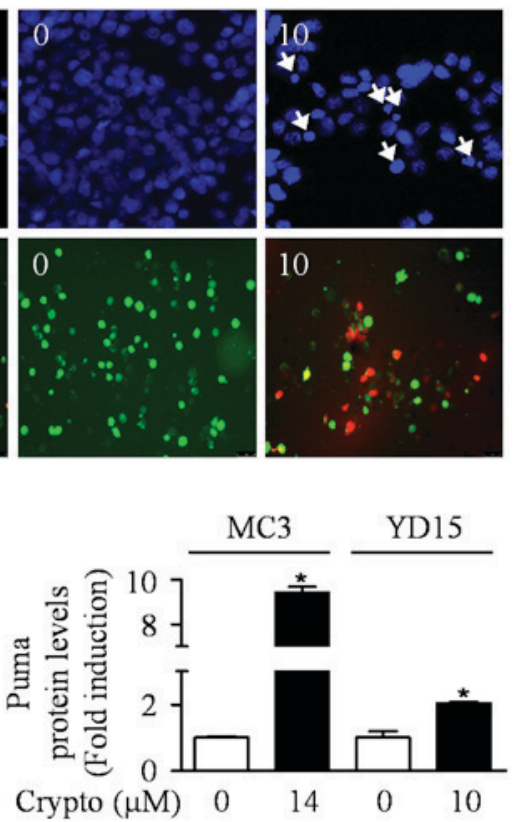

Figure 4. The effects of cryptotanshinone on apoptosis and PUMA expression in MC3 and YD15 cells. MC3 and YD15 cells were treated with DMSO or certain concentration (14 $\mu \mathrm{M}$ for MC3 cells, $10 \mu \mathrm{M}$ for YD15 cells) of cryptotanshinone (a potent STAT3 inhibitor) for $24 \mathrm{~h}$. (A) The effect of cryptotanshinone on cell viability was analyzed by trypan blue exclusion assay. The graph represents the mean \pm SD of triplicate experiments. ${ }^{* * * *} \mathrm{P}<0.001$ compared with $\mathrm{DMSO}$ treatment group. (B) Western blot analysis was performed to detect p-STAT3, total STAT3 and cleaved PARP. Actin was used to normalize the protein loading of each treatment group. ${ }^{*} \mathrm{P}<0.05,{ }^{* *} \mathrm{P}<0.01$ and ${ }^{* * *} \mathrm{P}<0.001$ compared with DMSO treatment group. (C) Cells were stained with DAPI solution as mentioned in Materials and methods (magnification, x400) (upper panel), and live (green) and dead (red) cells were determined by Live/Dead assay kit as mentioned in Materials and methods (magnification, x200) (lower panel). (D) The cell lysates were analyzed by western blot analysis using antibodies against Puma and p53. The graph represents the mean \pm SD of three independent experiments and significance compared with the control group was indicated ( $\mathrm{P}<0.05$ vs. control group).

MEPD-mediated apoptosis in MEC cell lines. To prove our hypothesis, we used a potent STAT3 inhibitor, cryptotanshinone. The results showed the dephosphorylation of STAT3 by cryptotanshinone significantly inhibited cell growth and increased apoptotic cell death in both MEC cell lines by enhancing the expression level of PUMA protein (Fig. 4). We also investigated whether cryptotanshinone affects p53 protein as an upstream molecule of Puma in MC3 and YD15 cells. However, p53 was not consistently affected by cryptotanshinone in both cell lines. In addition, we checked protein levels of Puma in STAT3 overexpression cells to clarify the relationship between STAT3 and Puma. The result showed that STAT3 overexpression slightly reduced MEPD-mediated Puma expression in both cell lines (data not shown). These results suggest that blocking STAT3 signaling pathway may contribute to apoptosis via induction of PUMA in both MC3 and YD15 cells.

\section{Discussion}

In order to kill the remaining cancer cells and prevent the recurrence, chemotherapy is essential following surgery. More than $50 \%$ of all available drugs on the market derived from natural sources including plants, microbes and marine life, of which over $70 \%$ of anticancer drugs have their origin from natural resources (25). Naturally Occurring Plant-based Anticancer Compound-Activity-Target database (NPACT) provide a thousand of natural resources exhibiting antitumorigenic activities which are experimentally validated (in vitro or in vivo) in various cancers (26). Thus, the discovery of pharmacologically active natural resources with antitumorigenic activity is very important for developing a new cancer medicine. A number of plant-derived natural compounds also has potential drug carriers for the treatment of oral cancer. For example, Impatiens balsamina L., a traditional herb medicine for the 
treatment of rheumatism, swelling and fingernail inflammation, regulates either AMPK or Akt signaling to promote apoptotic response in human oral cancer cell lines $(10,27)$. Our prior study has reported that Smilax china L. can induce apoptosis via the ERK signaling pathway to treat human MEC of salivary gland (28) and it gives notice of importance that natural compounds can be promising resources of new drugs for MEC in the future. In this study, we showed that one of natural resources, Potentilla discolor, caused blocked cell growth and induced apoptotic cell death in both MC3 and YD15 MEC cell lines. Recently, several Potentilla discolor-derived active components induced apoptosis in human HepG-2 hepatocellular carcinoma, MCF-7 breast adenocarcinoma and T-84 colon carcinoma cell lines (29). This is consistent with our findings that Potentilla discolor can have an ability to induce apoptosis in various cancers including MEC.

Natural products with anticancer properties may have various targets inside human cancer cells, but they often regulate the members of $\mathrm{Bcl}-2$ family which play a pivotal role in a programmed cell death process (30). Our group recently found that parthenolide increased Bim protein (28) and pycnogenol increased Bak protein by increasing its protein stability (31), resulting in the induction of apoptosis in human oral cancer supporting that natural products-derived compounds can influence Bcl-2 family members to exert their apoptotic activities in oral cancer. PUMA (p53 upregulated modulator of apoptosis) is one of BH3-only subgroup of the Bcl-2 family. A considerable amount of literature published on PUMA mentioned the involvement of PUMA in stress-induced apoptosis (32-35). Our results also here suggest that upregulation of PUMA by MEPD mediates apoptosis in human MEC cell lines. In addition, we screened the expression levels of other Bcl-2 family in MEPDtreated both cell lines; yet no Bcl-2 family proteins except PUMA were commonly regulated by MEPD during apoptotic condition (data not shown). PUMA was originally known as a downstream target of p53 protein. However, our western blot data showed no significant difference of p53 protein level after treatment of MEPD in human MEC cell lines (data not shown). It means p53-independent regulation of MEPD on PUMA protein during MEPD-mediated apoptosis in human MEC cell lines.

Signal transducers and activators of transcription 3 (STAT3) is one of a family of transcription factors that regulate apoptosis as well as cell proliferation, differentiation, and angiogenesis and a target for inducing apoptosis in various cancers $(36,37)$. Several studies have revealed the critical role of STAT3 in oral cancer development $(22,38,39)$. As previously stated from our laboratory, the inhibition of STAT3 by cryptotanshinone or sorafenib clearly induced apoptosis in human MEC cell lines or tumor xenograft $(40,41)$. In the present study, MEPD clearly inhibited STAT3 to induce apoptosis in human MEC cell lines and this observation may support other previous research demonstrating that STAT3 as a promising target for chemotherapy. In addition, inhibition of STAT3 by a STAT3 inhibitor (cryptotanshinone) in both cell lines significantly increased the expression of PUMA. Notably, prior study reported that STAT5 directly controls the expression of pro-apoptotic protein PUMA suggesting the possibility of the involvement of STATs in the regulation of PUMA protein. Although more research is required to determine direct interaction between
STAT3 and PUMA, this is the first time that STAT3 regulates PUMA to induce apoptosis in human MEC cell lines.

In conclusion, the present study revealed that MEPD caused a marked increase in salivary MEC cellular apoptosis in vitro. The molecular targets of MEPD-induced apoptosis were PUMA and STAT3. All these results should be useful in the search for naturally occurring plant-based new potential antitumor agents for the treatment of MEC.

\section{Acknowledgements}

This study was supported by the Basic Science Research Program through the National Research Foundation of Korea (NRF) funded by the Ministry of Science ICT \& Future Planning [2017R1A2B2003491].

\section{References}

1. Ettl T, Schwarz-Furlan S, Gosau M and Reichert TE: Salivary gland carcinomas. Oral Maxillofac Surg 16: 267-283, 2012.

2. Goyal G, Mehdi SA and Ganti AK: Salivary gland cancers: Biology and systemic therapy. Oncology 29: 773-780, 2015.

3. Zhang L, Li L, Wang Y, Liu Y and Li C: MC3 Mucoepidermoid carcinoma cell line enriched cancer stem-like cells following chemotherapy. Oncol Lett 7: 1569-1575, 2014.

4. Kingston DG: Modern natural products drug discovery and its relevance to biodiversity conservation. J Nat Prod 74: 496-511, 2011.

5. Newman DJ and Cragg GM: Natural products as sources of new drugs over the 30 years from 1981 to 2010. J Nat Prod 75: 311-335, 2012.

6. Hung HY, Qian K, Morris-Natschke SL, Hsu CS and Lee KH: Recent discovery of plant-derived anti-diabetic natural products. Nat Prod Rep 29: 580-606, 2012.

7. Tarkang PA, Appiah-Opong R, Ofori MF, Ayong LS and Nyarko AK: Application of multi-target phytotherapeutic concept in malaria drug discovery: A systems biology approach in biomarker identification. Biomark Res 4: 25, 2016.

8. Gupta SC, Kim JH, Prasad S and Aggarwal BB: Regulation of survival, proliferation, invasion, angiogenesis, and metastasis of tumor cells through modulation of inflammatory pathways by nutraceuticals. Cancer Metastasis Rev 29: 405-434, 2010.

9. Shin JA, Kim JJ, Choi ES, Shim JH, Ryu MH, Kwon KH, Park HM, Seo JY, Lee SY, Lim DW, et al: In vitro apoptotic effects of methanol extracts of Dianthus chinensis and Acalypha australis L. targeting specificity protein 1 in human oral cancer cells. Head Neck 35: 992-998, 2013.

10. Shin JA, Ryu MH, Kwon KH, Choi B and Cho SD: Downregulation of Akt by methanol extracts of Impatiens balsamina L. promotes apoptosis in human oral squamous cell carcinoma cell lines. J Oral Pathol Med 44: 420-428, 2015.

11. Zlotogorski A, Dayan A, Dayan D, Chaushu G, Salo T and Vered M: Nutraceuticals as new treatment approaches for oral cancer: II. Green tea extracts and resveratrol. Oral Oncol 49: 502-506, 2013.

12. Ramshankar V and Krishnamurthy A: Chemoprevention of oral cancer: Green tea experience. J Nat Sci Biol Med 5: 3-7, 2014.

13. Yang J, Chen H, Zhang L, Wang Q and Lai MX: Anti-diabetic effect of standardized extract of Potentilla discolor Bunge and identification of its active components. Drug Dev Res 71: 127-132, 2010.

14. Zhang L, Yang J, Chen XQ, Zan K, Wen XD, Chen H, Wang Q and Lai MX: Antidiabetic and antioxidant effects of extracts from Potentilla discolor Bunge on diabetic rats induced by high fat diet and streptozotocin. J Ethnopharmacol 132: 518-524, 2010.

15. Song C, Huang L, Rong L, Zhou Z, Peng X, Yu S and Fang N: Anti-hyperglycemic effect of Potentilla discolor decoction on obese-diabetic (Ob-db) mice and its chemical composition. Fitoterapia 83: 1474-1483, 2012.

16. Wen DS, Zhu XL, Guan SM, Wu YM, Yu LL and Wu JZ: Silencing of CXCR4 inhibits the proliferation, adhesion, chemotaxis and invasion of salivary gland mucoepidermoid carcinoma Mc3 cells in vitro. Oral Oncol 44: 545-554, 2008. 
17. Lee EJ, Kim J, Lee SA, et al: Characterization of newly established oral cancer cell lines derived from six squamous cell carcinoma and two mucoepidermoid carcinoma cells. Exp Mol Med 37: 379-390, 2005

18. Shankar S, Siddiqui I and Srivastava RK: Molecular mechanisms of resveratrol (3,4,5-trihydroxy-trans-stilbene) and its interaction with TNF-related apoptosis inducing ligand (TRAIL) in androgen-insensitive prostate cancer cells. Mol Cell Biochem 304: 273-285, 2007.

19. Yeh CC, Hsieh HL, Lee J, Jan YH, Lai TC, Hong CY, Hsiao M and Kuo MY: Polyethylenimine-mediated PUMA gene delivery to orthotopic oral cancer: Suppression of tumor growth through apoptosis induction in situ and prolonged survival. Head Neck 33 878-885, 2011.

20. Yang JG, Lu R, Ye XJ, Zhang J, Tan YQ and Zhou G: Icaritin reduces oral squamous cell carcinoma progression via the inhibition of STAT3 signaling. Int J Mol Sci 18: pii: E132, 2017.

21. Peng HY, Cheng YC, Hsu YM, Wu GH, Kuo CC, Liou JP, Chang JY, Jin SL and Shiah SG: MPT0B098, a microtubule inhibitor, suppresses JAK2/STAT3 signaling pathway through modulation of SOCS3 stability in oral squamous cell carcinoma PLoS One 11: e0158440, 2016

22. Brown ME, Bear MD, Rosol TJ, Premanandan C, Kisseberth WC and London CA: Characterization of STAT3 expression, signaling and inhibition in feline oral squamous cell carcinoma. BMC Vet Res 11: 206, 2015.

23. Niu G, Wright KL, Ma Y, Wright GM, Huang M, Irby R, Briggs J, Karras J, Cress WD, Pardoll D, et al: Role of Stat3 in regulating p53 expression and function. Mol Cell Biol 25: $7432-7440,2005$.

24. Hikisz P and Kiliańska ZM: PUMA, a critical mediator of cell death-one decade on from its discovery. Cell Mol Biol Lett 17: 646-669, 2012.

25. Chinembiri TN, du Plessis LH, Gerber M, Hamman JH and du Plessis J: Review of natural compounds for potential skin cancer treatment. Molecules 19: 11679-11721, 2014.

26. Mangal M, Sagar P, Singh H, Raghava GP and Agarwal SM: NPACT: Naturally occurring plant-based anti-cancer compoundactivity-target database. Nucleic Acids Res 41: D1124-D1129, 2013.

27. Shin JA, Kwon KH and Cho SD: AMPK-activated protein kinase activation by Impatiens balsamina L. is related to apoptosis in HSC-2 human oral cancer cells. Pharmacogn Mag 11: 136-142, 2015.

28. Yu HJ, Shin JA, Lee SO, Kwon KH and Cho SD: Extracellular signal-regulated kinase inhibition is required for methanol extract of Smilax china L.-induced apoptosis through death receptor 5 in human oral mucoepidermoid carcinoma cells. Mol Med Rep 9: 663-668, 2014.

29. Zhang J, Liu C, Huang RZ, Chen HF, Liao ZX, Sun JY, Xia XK and Wang FX: Three new C-27-carboxylated-lupane-triterpenoid derivatives from Potentilla discolor Bunge and their in vitro antitumor activities. PLoS One 12: e0175502, 2017.
30. Christodoulou MI, Kontos CK, Halabalaki M, Skaltsounis AL and Scorilas A: Nature promises new anticancer agents: Interplay with the apoptosis-related BCL2 gene family. Anticancer Agents Med Chem 14: 375-399, 2014

31. Yang IH, Shin JA, Kim LH, Kwon KH and Cho SD: The caspase 3-dependent apoptotic effect of pycnogenol in human oral squamous cell carcinoma HSC-3 cells. J Clin Biochem Nutr 58: 40-47, 2016.

32. Yang S, Zhu Z, Zhang X, Zhang N and Yao Z: Idelalisib induces PUMA-dependent apoptosis in colon cancer cells. Oncotarget 8: 6102-6113, 2017.

33. Chatwichien J, Basu S, Budina-Kolomets A, Murphy ME and Winkler JD: PUMA-dependent apoptosis in NSCLC cancer cells by a dimeric $\beta$-carboline. Bioorg Med Chem Lett 26: 4884-4887, 2016.

34. Zhu HJ, Liu L, Fan L, Zhang LN, Fang C, Zou ZJ, Li JY and $\mathrm{Xu} \mathrm{W}$ : The $\mathrm{BH} 3$-only protein Puma plays an essential role in p53-mediated apoptosis of chronic lymphocytic leukemia cells. Leuk Lymphoma 54: 2712-2719, 2013.

35. Zhang Y, Xing D and Liu L: PUMA promotes Bax translocation by both directly interacting with Bax and by competitive binding to Bcl- $\mathrm{X}_{\mathrm{L}}$ during UV-induced apoptosis. Mol Biol Cell 20: 3077$3087,2009$.

36. Xiong A, Yang Z, Shen Y, Zhou J and Shen Q: Transcription factor STAT3 as a novel molecular target for cancer prevention. Cancers 6: 926-957, 2014

37. Al Zaid Siddiquee K and Turkson J: STAT3 as a target for inducing apoptosis in solid and hematological tumors. Cell Res 18: 254-267, 2008.

38. Mali SB: Review of STAT3 (Signal transducers and activators of transcription) in head and neck cancer. Oral Oncol 51: 565-569, 2015.

39. Leeman-Neill RJ, Seethala RR, Singh SV, Freilino ML, Bednash JS, Thomas SM, Panahandeh MC, Gooding WE, Joyce SC, Lingen MW, et al: Inhibition of EGFR-STAT3 signaling with erlotinib prevents carcinogenesis in a chemically-induced mouse model of oral squamous cell carcinoma. Cancer Prev Res 4: 230-237, 2011.

40. Yu HJ, Park C, Kim SJ, Cho NP and Cho SD: Signal transducer and activators of transcription 3 regulates cryptotanshinoneinduced apoptosis in human mucoepidermoid carcinoma cells. Pharmacogn Mag 10 (Suppl 3): S622-S629, 2014

41. Yu HJ, Shin JA, Jung JY, Nam JS, Hong IS, Cho NP and Cho SD: Inhibition of myeloid cell leukemia-1: Association with sorafenib-induced apoptosis in human mucoepidermoid carcinoma cells and tumor xenograft. Head Neck 37: 1326-1335, 2015.

This work is licensed under a Creative Commons Attribution-NonCommercial-NoDerivatives 4.0 International (CC BY-NC-ND 4.0) License. 